Biomed.

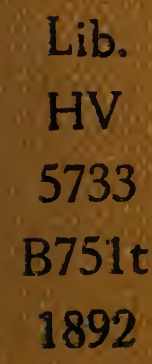

떰

1

輅

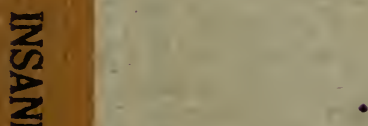




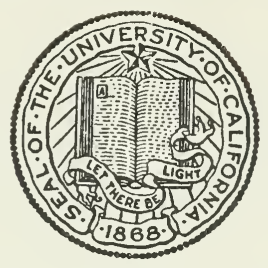

THE LIBRARY OF THE UNIVERSITY OF CALIFORNIA LOS ANGELES 



\section{TOB A CCO,}

\section{IBSANTIY and NERVOUSNESS.}

\section{DR. L. BREMER,}

LATE PEISICIAN TO THE ST. VINCENT'S INSTITUTION FOR THE INSANE, OF ST. LOUIS, MO.

PIRICE, FIFTEFI CHNTS.

PUBLISHED BY THE

MEYER BROTHERS DRUGGIST, ST. LOUIS, MO. 
1e Contents of this Pamphlet are based on an le read before the St. Louis Medical Society in ber, 1891. At the request of friends and jerinterested in the subject the author has agr ed large and modify the article, and to publis it z present form.

Lous, December 22, 1891.

L. Brener, M. D 


\title{
TOBACCO, INSANITY and NERVOUSNESS
}

\author{
B Y \\ DR. L. BREMER, \\ OF ST. LOUIS.
}

There is no narcotic, either in modern or ancient times, which has been and still is, so universally in use, as tobacco, and there is none about whose action on the human body there is so much difference of opinion among the laity and the profession.

Whereas, by some, it is looked upon as an immitigated eril, it is claimed by others, that its use is not without adrantage. Hence, it has been condenmed and commended in turns. Its friends have, so far, carried the day; it triumphal march over nearly the whole civilized and uncivilized globe has been continuous.

Without entering into preliminaries and details, I will state at the outset, that I side with those who, looking at the injurious effects collectively, consider it more harmful than alcohol, from the simple fact that its use is more general, its effects more gradual and less obvious, and that, from a moral point of view, it is in better standing.

The breath of tobacco is held permissible and will be trondoned by all classes; that of alcohol is looked upon as odious and exposes its bearer in some quarter's to social costracism.

It is this connivance, on the part of public opinion, at this kind of luxus-consumption, as it is euphoniously styled 
by modern physiologists, that fosters its spread, especially anongst those who can least afford to offer any insult to their nervous systems. And unfortunately it is just this class of persons who delude themselves into the belief, that tobacco is indispensable to them. With advancing civilization it is considered necessary by many to use a sedative or a stimulant of some sort as a kind of a safety-valve for the growing nervousness of our age.

Thus, by many smokers it is thought that after bodily or mental exertion an equilibrium of all the functions is re-established by the pipe, cigar, or plug. Its action, therefore, is somewhat like that of coca ${ }^{*}$ in its pleasant effects.

'This is the case in the healthy smoker as long as he keeps within certain limits. But it is quite different with the vast and ever-increasing army of neurasthenics and psychopaths of our days.

Our ancestors were evidently not so deleteriously affected either by alcohol or tobacco, as modern man is, with the strain of the requirements of a more complicated life weighting upon him, and handicapped, as he frequently is, in his nervous and psychical make-up.

It is specially of the effect of tobacco on this latter class that I wish to speak in the following remarks, and to start with, I venture the broad assertion, that, whereas the

* The pernicious influence of this drug is also spreading at an aiarming pace among the well-to-do. 'The various proprietary preparations which go by the name of "Wine of Coca" and which, to the detriment of many, have been indorsed by physicians in good standing, are constantly working havoc among neurotic persons who believe they can take this kind of wine with the same impunity as they can alcohol in some form. Only too late they find that one tablespoonful of the stuff calls for another and that a constant vague, half-conscious feeling of misery pushes them with the relentlessness of fate to the baneful bottle. Why do not the physicians, if coca is indicated, use the reliable fluid extract and have it taken in Madeira wine instead of wing and abetting a nefarious traffic, which they do by prescribing

rietary wines of coca? 
robli:t and healthy, especially if he lead an active outdoor life, " may use blocco in its various forms with apparent impunity, $i . \epsilon$. without experiencing any demonstrable dum to boly or mind, the neurasthenic and the 1 -wopath har e no business either to smoke or chew.

But it is just persons of this category (who are often not at all arare of their morbid condition) that become such absoluta and 1 owerless slaves to the habit. They fall victims to it er.rly in life as a rule. Whilst the healthy lumatrani u revolts against the drug as intensely as tim at it dog a cat, and has to gradually accustom itself to overcone tle unpleasant sensations accompanying the fir 3 t attempts a using it, the born neurasthenic often takes to it as the yo ig duck does to water. Only in this manner (c) the liser ar phenomenon of infant-smokers be explained, if w e does not prefer to look upon such per$r e r=i o n$ of 11 ite as a species of precocious moral insanity inlerited from , arents who are generally not ouly excessive tubacro-users, lut evidently mentally defective.

Nutr, I do n it believe that, with approaching maturer your I am one f those who eye through pessimistic specta"4 en tha rising or neration, but I simply repeat the every-day 4loservation, wis ch I have never seen doubted or contra-

Nothing peus to eliminate nicotine so quickly as muscular exertion,

It is strange an would be amusing to the observer, were it not such a stricus multer, to see the delusion on the part of many young neurasthence who magine that they have a great cleal of nerve force. It is

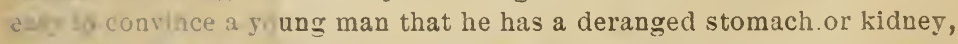
etr. when the symptoms are present; but a statement that his nerves ago brain ar helo $\mathbf{v}$ par, and that tobacco is rank poison to him, is recelved with more $r$ less incredulity. Thus, a young man, a patient of nime, hew that on rarious occasious, after excesses in smoking, he had has oplep/ ic atlack s of a grave and pronounced character. Yet he considand ils nerves strong, because he was energetic; after periods of austueuce ho. woul indulge in smoking for the sake of sociability, al ways with the -ame result. 
dicted, that there is an alarming increase of juvenile smokers; and, basing my assertion on the experience, gathered in my private practice and at the St. Vincent's Institution of this city, I will broadly state that THE BOY wHO sMOKEs AT SEVEN, WILL DRINK WHISKEY AT FOURTEEN, TAKE TO MORPHINE AT 20 OR 25, AND WIND UP WITH COCAINE AND THE REST OF THE NARCOTICS, AT 30 AND LATER ON.

It is like a pathologico-moral version of Hogarth's “ The Rake's Progress."

It may look like overstating and exaggerating things, but I know whereof I speak, when I say that tobacco when hahituaily used by the young leads to a species of imbecility; that the juvenile smoker will lie, cheat and steal, which he would not, had he let tobacco alone. This kind of insanity I have observed in quite a number of cases at the St. Vincent's. The patients presented all the characteristics of young incorrigibles. They had exhausted the indulgence of their parents, who saw no other way to protect them from their insane pranks, than to commit them to the institution. Had they been less favorably situated financially, they would have landed at the House of-Correction or the Workhouse.

I do not know whether a lasting inprovement was effected in any of them. There was not one amongst them that was able to comprehend that tohacco was injuring him : they were constantly on the lookout for obtaining it, by begging, stealing or bribing, and regarded the deprivation of the drug as a punishment. The sense of propriety, the faculty of distinguishing between right and wrong, was lost.' The father of one of then who looked upon his son only as an aggravated case of bad boy, told me that he. himselfhad been smoking ever since his 10th year and it never had affected him. In, reality, being only 45 years old, he was a wreck, physically and mentally, though he came of healthy stock. He coutd not or would not comprehend 
that tobacco was gradually undermining his own mind and body, although his wife and his friends knew and saw it.

But it is not only in the young, that the use of tobacco is followed with such disastrous effects. Smoking or chewing, when commenced in the period of manhood, and even at the time it generally does least harm, after middle age, will tell on the mind if excessively indulged in. Is it to be wondered at, that a drug which, until tolerunce is established, has such potent and palpable effects as to produce loss of co-ordination and unspeakable malaise, and after the organism has become used to it, is capable of setting up the well-known heart disturbances, amblyopia and even amaurosis - which, in short, possesses the characteristic qualities of a powerful nerve poison, is it a wonder if such drug, when, in spite of the warnings on the part of various organs, excessively and persistently used, finally produces one or the other form of insanity? A drug that can, as has been demonstrated, cause organic changes of the optic nerve, which, I hardly need mention it, is, in reality, not a nerve, but a protrusion of elongation of the brain itself must certainly be capable of injuriously influencing other and functionally higher, parts of the organ of the mind.

Dr. Kjelberg real before the section of Neurology and Psychiatry of the last International Congress, a paper in which he described a nicotine-psychosis, well marked by definite symptoms and stages. I have never seen the clinical picture as drawn by this observer, but it always seemed to me that whenever tobacco entered at all as a factor in a case of insanity, it was the immediate cause, vivifying, uniting and condensing, as it were, the dormant morbid elements which predisposed the individual to mental disturbance. Thus I have seen melancholia, more often mania, and very frequently general paresis hastened and 
precipitated by excessive use of tobacco. I know, however, of instances where the last named disease, or "softening of the brain," as it is called by the lay-public, could not be referred to any other cause but tobacco.

That the majority of the insane smoke or chew is too well known to deserve special mention. Some alienists have been of the opinion that this habit ought not to be discouraged, that it has a calming and pacifying effect especially on the chronic insane. I believe this to be the case in some of the secondary dements, but ordinarily, though calming at first, it has an exciting effect later on. True, if the temporary contentment resulting from the gratification of the craving of the patient is looked upon as the action of tobacco, I agree that its effects are calming. But this quieting down, in my opinion, takes place on the same principle that a child gets quiet and stops crying when its wish, even though most unreasonable, is gratified. The rule is, that smoking causes or prolongs excitement in the insane. Many become absolutely unmanageable as soon as they touch tobacco. They get quarrelsome, tease and molest their fellow-patients and render themselves obnoxious generally.

That tobacco really does cause insanity is evidenced by the magic effect seen in some cases after the discontinuance of the drug, when the patient's condition is still such that he is not wholly inaccessible to reason and has will power enough to abandon the habit. Thus I have seen that beginning melancholia with suicidal impulses, hallucinations of various kinds, forced actions, besides, the precursory symptoms of insanity, such as insomnia, crying spells, praecordial anxiety, fears of impending evil, "that something is going to happen," impotency, vertigo, beginning impairment of memory and judging power, and even the lowering of the moral tone, all of which, and a host of other symptoms were attributable to chronic tobacco- 
intoxication, disappeared after freedom from the habit was establisherl.*

But whenever a case has gotten so far, that commitment to an institution has become necessary, the prospects are not so good, because such persons, as a jule, cannot be convinced that tobacco is, or has been, the cause of their mental trouble. Their argument is that almost everybody smokes, that all their friends and acquaintances chew or smoke, without showing any symptoms of insanity. The

* One of my patients experienced among other morbid symptoms an almost uncontrollable desire to throw himself out of the window, whenever he had to go to the upper stories of the house in which he was emplored; this impulse was so orerpowering that he did not dare to approach the windows and was in mortal fear of high places. He was a smoker and a neurasthenic. The discontinuance of the drug terminated bis morbid impulses and fear.

¥ This is an argument which it is hard to invalidate, because the smoker does not appreciate the law of difference and variability of the resisting power on the part of the organism, although this law is a matter of every-day obserration. While some persons seem to be proof against almost any injurious agencies, others will yield on the slightest occasion, to much less powerful influences, mechanical, toxic, or morbific in the stricter sense. Again, the susceptibility to injury varies in the same individual. What is true of individuals applies with equal force to nations. Thus, the Germans have been called a nation of thinkers and smokers, and, seemingly, their smoking habits have not interfered with their power for logic, nor, for that matter, [except a generally prevaling short-sightedness] with their physical constitution. This has, for a long time, puzzled the French, who have tried to account for the dire effects of tobacco on their own countrymen in various ways. Some investigators think this difference in effect is due to the difference in the manner of raising tobacco in the two countries, and the different percentage of nicotine thus obtained. The Germans, on the other hand, are dumbfounded at the amount of alcohol which the Rinsian consumes apparently without injury.

This discrepancy, in effect, is certainly not a matter of difference in quality. As remarked before, all this is a question of resisting power produced and gorerned by racial, social, climatic, industrial and a number of other more or less occult influences. Now, all observers agree that in our country many conditions conspire to make us a nervous people, to produce what haseren heen styled, "American nerrousness." 
alcoholic insane when leaving the institution to entel active life again, generally knows and admits that alcohol has been the cause of his mental break-down, the nicotine-victim does not admit anything.

There has been a movement on foot in the medical press, and to some extent in the daily papers, which latter chronicle the fer cases that come to public knowledge under the head: "Gone insane from cigarette-smoking,",* etc., to counteract the spread of this fatal habit, fatal to the individual himself and pernicious to the coming generation: but so far, apparently without any appreciable result.

French medical observers are of the opinion that one of

This "nelvousness" in other words means a weakness, an instability, a vulnerability of the nervous system. Add to this the unquestiouably strong quality of the tobacco which the taste of the American public exacts from the manufacturer, and it becomes plain that there exist two cogent reasons why we should be on our guard vis-a-vis the indiscriminate use of the article.

* Whether there is a constituent in the cigarette endowed with special properties as a nelve and brain-poison, I have not been able to ascertain. My friend, Dr. J. C. Mulhall, of this city, in a paper read before the Medico-Chirurgical Society several years ago, claimed that it was the cheapness and easy acquisition of the article and consequently its unbounded consumption, that rendered it so pernicious, especially to the young, and that its contents differed in no way from other tobacco. I have no doubt that pecuniary consideratious and the temptation to fill the little scraps of time with smoking contribute largely to the lamentable effects of cigarette consumption: but the resuit of my inquiries among former victims of the cigarette habit leads me to believe that the action of cigarette smoke on the nervous system is totally different from that of the cigar. I hope for the sake of humanity that the charge so often made that opium is used in cigarette manufacturing cannot be substantiated. If true, it would constitute the lowest depth of commercial infamy. However this may be, one thing seems to be generally conceded, that is the well-nigh universal habit of cigarette smokers to "inhale" and thus to multiply the chances of nicotine-absorption. Possibly it is on this account that moral and intellectual blight befalls so often the juvenile habitue and that the adult victim in time becomes id dgety and cranky, sometimes barely able to move along the narrow strip of the borderland of insanity. 
the factors causing the depopulation of France is the excessive use of tobacco by its inhabitants; for the offspring of inveterate tolacco consumers is notoriously puny and stunted in stature and lacks the normal power of resistance, especially on the part of the nervous system; again, in our country it is a significant fact that an astounding percentage of the candidates for admission to West Point and other military schools are rejected on account of tobacco-hearts; from all countries and from all classes of society come reports in increasing numbers of the baneful effects of the tobacco-habit.

But the consumption goes on and will do so, until an examıple is set by those who, above all others, can estimate the disastrous effect of the habit.

If teacher's, preacher's and physicians would pronounce the anathema on tobacco and abstain from it themselves, others would follow. But here is the difficulty. It is only exceptionally that a smoking pedigogue, clergyman or physician can be convinced that he would be a better man physically, intellectually and morally, if he would give up tobacco, and that he has no idea what capabilities of wellbeing he possesses, if he only could muster up moral courage enough to abandon the use of a drug which in nine cases out of ten produces, to say the least, a vague sensation of uneasiness and restlessness, which only too often calls for a remedy that will do away with these effects, and that is alcohol. Some are aware that tobacco alone is responsible for a continual malaise or misery, especially when their attention is called to it by others, but like the cocainist, who asserts that the effects of cocaine are horrible, and still goes on, using the poison, so the tobacco-slave is bound, as by fate, to again indulge in a drug which he knows causes him to suffer.*

* It must be a strangely potent fascination indeed, which tobacco exercises over the bulk of its rictims, when we consider that some are aware 
Some, however, labor under the delusion that it increases their working power, that the flow of thought becomes easier, and that without tobacco they are unable to do any mental work. Instances are cited by them of great men, inveterate and excessive tobacco consumers, who left their mark in the history of civilization as savants, artists, etc. They do not consider the possibility that these men accomplished what they did in spite, but not in consequence of, or aided by, their habit.

Students of chronic nicotine-intoxication are convinced that the great men among the tobacco slaves would have been still greater, had they never used the drug. Thus, Kant, the most eminent of German philosopher's, is said to have written such an obscure and unintelligible style, because he smoked and snuffed to excess. I myself know of a medical man who wrote a great book, which labors under the same defect as Kant's works, because of his slavery to tobacco.

But these things are trifles when compared with the destructive and degenerative influences the drug exerts on the broad masses.

that tobacco is at the bottom of all their ailments. The question naturally arises in this connection: why do people smoke, when they kuow that as soon as they touch tobacco, they experience immediately its toxic effects? Many a smoker rises in the moruing bright and energetic: the vicotine absorbed during the previous day has been eliminated from his tissues - thanks to his well-meaning and powerful excretory organs. He smokes his first cigar after breakfast, becomes at once restless, dissatisfied, peevish and disagreeable; the cigar stamps its siguature on his mind for the rest of the day. This is the experience of many a neurotic smoker, and yet he will resume the practice day after day, making his own life a burden and rendering everybody around him miserable. It is easily intelligible why some persons take alcohol; this is primarily a stimulant and secondarily a paralyzant, but tobacco paralyzes at once: it lowers all the faculties except those of fancy, and tobacco-phantoms are not of much value. The downfall and general backwardness in civilization so characteristic in the Oriental people is largely due to their dreamy disposition engendered by abuse of tobacco. 
There is only one way to lessen the evil - it is the dissemination of knowledge of the baleful effects of tobacco among the rising generation, initiated and sustained by the three professions mentioned above. Of course they ought practice first, what they are going to preach.

But is there much prospect of such a movement at present? I think not. I know of schools conducted by the clergy, in which smoking is not only permitted to fourteen year's old - and even younger boys - but more or less encouraged. I believe that its well known anaphrodisiac effect, on account of which it was very popular among the monks of Italy, several centuries ago, is possibly a reason for the favor in which it is held at the present day in some quarters.

Again, I know of physicians who not only smoke to excess themselves or still worse, indulge to a morbid extent in the unmannerly habit of chewing, but permit and even encourage their own children to smoke. One of them was in the habit of awarding his 13 -year-old son by extra-good, $i . e .$, extra-strong cigars for high numbers in school. It is hardly necessary to add what became of this boy. He is now a periodical inmate at various sanitariums for a combination of bad habits.

And the teachers? They are not lagging behind in contributing to the army of tobacco slaves; there are few that raise their voices against the habit, for the very valid reason that they are not fully cognizant of its evil effects and smoke as much themselves as men in other vocations.

In view of such discouraging facts I hardly expect much good from this contribution and testimonial to the pernicious effects of tobacco, because the truth has not dawned upon the multitude yet. As in the body politic, evils will run their course, until there is a general uprising of common sense which disposes of them, so with the irrational and excessive use of tobacco, which will probably go on 
increasingly, until a limit of endurance is reached, and the disastrous results of the abuse become patent enough to impress even the dullest mind.

But under existing conditions the habit will not want for new generations of victims, as long as the cigar is looked upon as a symbol of manliness hy the young, and the pipe as that of peace and comfort by the adult, and as long as tobacco is praised in word and picture. To what extent the habit is fostered among boys on the theory of forbidden fruit, it is not my province to discuss.

This paper was designed to bring before this Society and the profession at large my views on a subject with which unusual opportunities have made me familiar. Imperceptibly I have drifted from the role of the author of a paper into that of a moralist and exhorter, and yet I know what an unpopulur figure the man cuts that has the slightest suspicion of a reformer about him. My consolation is that I foresee the results of these remarks on my readers. One will say witb a pitying smile: All true, but exaggerated.

Another one who reads this will be convinced of the correctness of some points as applying to his own case. He will fling his freshly-lit cigar away with the firm resolve of quitting the weed forever. The effect is immediate. In a few days he feels that his mental and physical energies are wonderfully strengthened; there is a buoyancy of spirits, a return of healthy animal life, which he has not experienced for many a year and, one fine day, when he feels particularly bright and happy over so wonderful a change, he celebrates the event and - lights another cigar. The Angel of Constancy veils his face, and the same train of the old familiar symptoms of neurasthenia aud mental depression, of irritability and don't-know-what's-the-matter-feeling take a renewed and firmer hold of him.

So I fear I shall share the fate of the preacher in the desert. 
But may be, that one or the other tobacco-user comes to the conclusion that he shows some of the symptoms detailed above himself, and that he resolves to quit; is there, in this case, any danger in the abrupt discontinuance of the drug, as there is in quitting the habitual use of alcohol or morphine, for instance?

$\mathrm{My}$ experience is that there is none. By" "tapering off ", the combat would be unnecessarily prolonged.

It is not well to make a compromise for him, who has already begun to suffer from outspoken toxic effect: of nicotine, and to simply decrease the daily allowance of tobacco. Many a smoker is astonished to hear from his physician that even the two or three cigars he is smoking now, keep him in the wretched state he complains of, when a dozen and more in former years did not affect him.

The explanation of this paradox is very simple. Through chronic poisoning, or a long series of acute and sub-acute attacks of nicotine intoxication he has lost all resisting power and, like the broken-down alcoholic, who used to drink a quart or more of whisky a day, and, when his nerves are shattered by the abuse gets pathologically drunk and fuddled on one ounce, so the nicotine-invalid is completely unnerved by one or two cigars.

A stumbling-block to good resolutions proves often the following mistake which is quite prevalent: Many smokers who are told that tobacco is at the bottom of their ailment and who finally believe it and act on this belief, expect that with abolishing the cause, the effect will cease immediately, that they will jump with both feet into perfect health on quitting tobacco: They do not consider that the mischief done by a chronic disease of any kind to the organism, it takes months, nay, year's, to undo by strict hygienic living. Tobacco-cachexia in its various forms, is no exception to the rule.

Lastly: Are there means by which the abandoning of 
the drug may be faciiitated? Yes. But of paramount importance is the firm resolution to quit. This being settled, a combination of the bromides, Indian hemp and bitter tonics will easily tide the patient over the gnawing sensation and general uneasiness of the tobacco-hunger. 

UNIVERSITY OF CALIFORNIA LIBRARY

Los Angeles

This book is DUE on the last date stamped below.

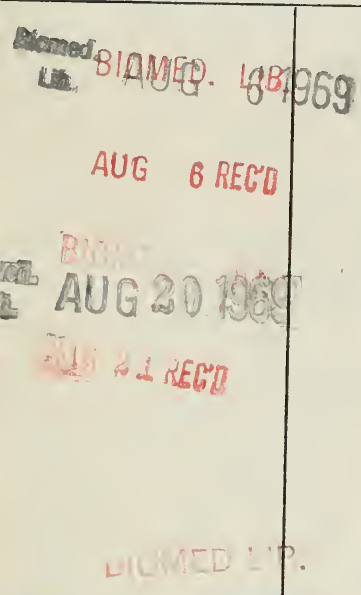

MED JAN 5,1978

$1 / 19 / 78$

IOMED FEB 24 '

AED MAR $09^{\prime} 88$

BONEL LIS

IAR 101988

m L9-116m-8,'62(D1237s8) 444
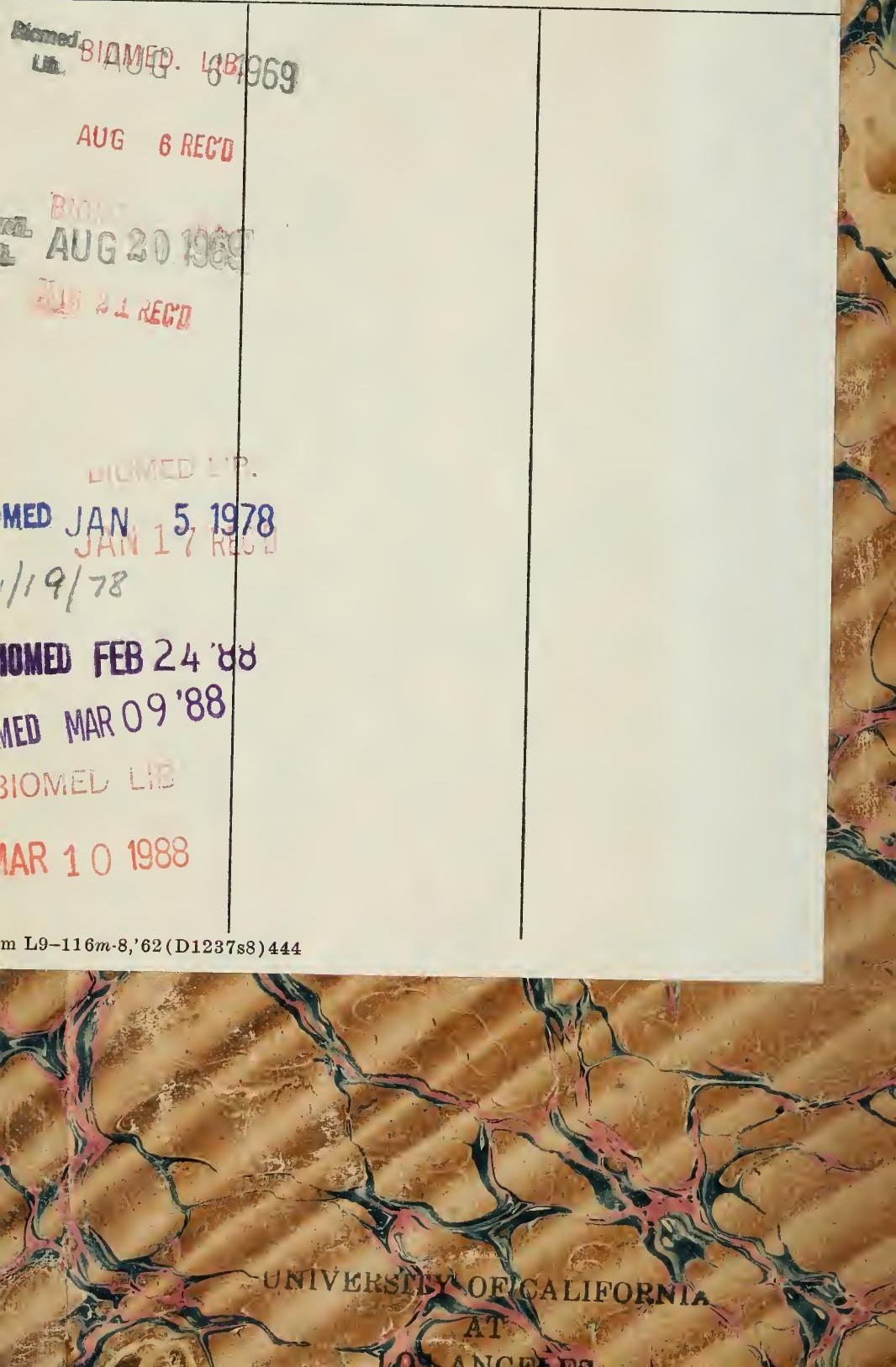
